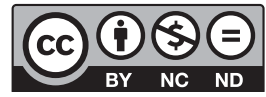

Estudos Teológicos foi licenciado com uma Licença Creative Commons Atribuição - NãoComercial - SemDerivados 3.0 Não Adaptada

http://dx.doi.org/10.22351/et.v58i2.3440

\title{
Dios ENTRE-MEdio DE LAS FRONTERAS: HACIA UNA TEOLOGÍA PÚBLICA POSCOLONIAL ${ }^{1}$
}

God in-between the frontiers: towards a postcolonial public theology

Nicolás Panotto ${ }^{2}$

Resumen: El presente artículo tiene por objetivo introducir algunas nociones generales de la teoría poscolonial, especialmente en Homi Bhabha, para ser aplicadas a una relectura de las dinámicas socio-políticas contemporáneas, y con ello acercarnos a un concepto sobre lo público. Estas nociones nos permitirán proponer una teología pública poscolonial a partir, principalmente, de una "teología sobre Dios" (o más concretamente, una poscolonización de lo divino), donde se presentarán algunos abordajes sobre la relación entre religión y política, y con ello sobre procesos más amplios en el espacio público.

Palabras claves: Poscolonialismo. Teología Pública. Política. Religión.

Abstract: The present article aims to introduce some general notions of postcolonial theory, especially in Homi Bhabha, to be applied to a re-reading of contemporary sociopolitical dynamics, and thus approaching a concept about the public. These notions will allow us to propose a postcolonial public theology starting, mainly, from a "theology of God" (or more specifically, a postcolonization of the divine), which proposes some approaches on the relationship between religion and politics, and with this on wider processes in the public sphere.

Keywords: Postcolonialism. Public Theology. Politics. Religion.

\section{Introducción}

Los estudios poscoloniales irrumpieron el campo del análisis socio-cultural como un marco que pretende abordar pero también superar diversos reduccionismos propios de los ejes epistémicos en boga dentro de la academia occidental, reinantes

\footnotetext{
1 O artigo foi recebido em 27 de agosto de 2018 e aprovado em 05 de outubro de 2018 com base nas avaliações dos pareceristas ad hoc.

2 Argentino. Licenciado en Teología, Magister en Antropología Social y Política, y Doctorando en Ciencias Sociales. Director del Grupo de Estudos Multidisciplinarios sobre Religión e Incidencia Pública (GEMRIP). Investigador Asociado del Instituto de Estudios Internacionales de la Universidad Arturo Prat (Chile). Contacto: nicolaspanotto@gmail.com
} 
principalmente durante el siglo XX. Por una parte, dan cuenta y se adentran al análisis de la complejidad de los agentes, dinámicas e interacciones que componen un espacio social, lo cual conlleva problematizar las categorías analíticas tradicionales, no sólo en términos de demarcación de los fenómenos sino, principalmente, sobre la imposibilidad de obtener marcos descriptivos categóricos y homogéneos, como las ciencias sociales y humanas modernas a veces pretenden. De aquí que agencia, interculturalidad, sujeto/identidad, entre otros, se transforman en condiciones predominantes de estudio para esta corriente. Pero por otra parte, el poscolonialismo inscribirá estos procesos en una matriz socio-histórica que reconoce la presencia aún vigente de lógicas coloniales, es decir, de prácticas sociales, dinámicas geopolíticas y fenómenos culturales cuyo origen se retrotrae a las fronteras y tensiones inscritas por la empresa colonial en inicios de la era moderna, la cual, lejos de irse, ha mutado en nuevos rostros dentro de nuestra sociedad global contemporánea.

La teología poscolonial se adentra a esbozar lecturas alternativas desde la teología cristiana a partir de estos procesos, no sólo del lugar del fenómeno religioso en dicha trama sino también desde una epistemología teológica que asume desde su especificidad -y su propio objeto: Dios-, su legado colonial y moderno, pero también la condición resignificante dentro o desde esos mismos límites. En este sentido, la teología cristiana se reconoce en esa ubicación "entre medio", donde las imágenes divinas, las prácticas misionales y los modelos de espiritualidad, se mueven entre la posibilidad de ser funcionales al imperialismo religioso y político, como también instancias imbuidas en la agencia subalterna, la reflexión contextual y el compromiso radical desde lo excluido por la propia matriz colonial, trayendo consigo nuevas imágenes de Dios y relatos teológicos disruptivos que deconstruyen el estatus ontológico de los sistemas imperantes.

En este artículo asumimos que dicha deconstrucción plantea una dimensión intrínsecamente política dentro del quehacer teologal. Por ello, nos adentraremos a producir un diálogo entre dos mundos que nos sirvan como posible propuesta de puente, a saber, la teoría/teología poscolonial y la teología pública. Más concretamente, queremos proponer una teología pública como un marco hermenéutico poscolonial. ${ }^{3}$ Nuestra tesis será la siguiente: así como el concepto de poscolonialidad propone una lectura posfundaciona ${ }^{4}$ de las relaciones sociales, adentrándose a una crítica del locus ontológico de las dinámicas coloniales, de la misma manera una lectura teológica

3 CHUNG, Paul. Postcolonial public theology. Oregon: Cascade groups, 2016.

4 Con posfundacional nos referimos al abordaje filosófico que critica la sutura ontológica de cualquier discurso o cosmovisión que se dice fundacional, es decir, como marco único e incuestionable de sentido. El posfundacionalismo no niega la existencia de marcos cosmovisionales particulares, pero sí problematiza la existencia de un fundamento único y clausurado para comprender los procesos de cambio histórico. Más bien, se apela a la presencia de una diversidad de marcos de sentido que interactúan entre sí y forman parte de un espacio que los excede desde el encuentro con lo Otro. En resumen, una crítica posfundacional implica el cuestionamiento del régimen epistémico de un discurso, de una práctica o de un dispositivo institucional, a partir del locus de pluralidad y diversidad a partir de otros-modos-de-ser que interpelan todo posicionamiento. Ver MARCHART, Oliver. El pensamiento politico posfundacional. Buenos Aires: FCE, 2009. p. 204. 
poscolonial nos lleva a una crítica teológica posfundacional sobre la persona divina, que trae consigo una epistemología focalizada en la transformación social, es decir, nos orienta a una teología pública que prioriza la deconstrucción de la persona divina como punto de partida.

\section{(Con)vivir-entre-medio: lo público y su condición poscolonial}

El pensamiento poscolonial responde a diversas ramificaciones: los estudios subalternos en la India ${ }^{5}$, el desarrollo del poscolonialismo como disciplina ${ }^{6}$ y el llamado giro decolonial, que es el rostro latinoamericano de esta propuesta. ${ }^{7}$ Las tres corrientes mencionadas tienen sus particularidades, énfasis, diferencias y hasta oposiciones. Pero podríamos destacar un marco común de lectura entre los tres abordajes, y es que vivimos en un mundo demarcado por la historia colonial, cuyas delimitaciones se traducen en concepciones antropológicas, dispositivos epistemológicos y dinámicas de poder institucionalizados que permanecen hasta hoy; pero estos escenarios distan de ser homogéneos e impenetrables ya que en el entre-cruce de estas localizaciones, existe un fondo arenoso donde las lógicas coloniales son deconstruidas y subvertidas a partir del incontable número de agencias, sujetos, institucionalidades y discursos contra-hegemónicos que habitan los márgenes de la propia colonialidad. En otras palabras, la heterogeneidad inscrita en un contexto poscolonial se transforma en un campo que implosiona ${ }^{8}$ desde adentro de las propias lógicas coloniales.

Para el propósito de este artículo, nos detendremos más concretamente en tres propuestas analíticas realizadas por el filósofo indio Homi Bhabha, uno de los referentes de la teoría poscolonial, que nos servirán para elaborar una propuesta que denominaremos como espacio público poscolonial. Nos referimos a los conceptos de localidades entre-medio, mímesis colonial y ética del reconocimiento. Con respecto al primero, la idea de entre-medio tiene por objetivo problematizar los abordajes dicotómicos propios de la modernidad colonial, como los representados por las distinciones teoría-práctica, desarrollo-subdesarrollo, progreso-retraso, burgueses-radicales, etc. Los entre-medio son espacios que habitan las fronteras entre los sentidos instituidos, forjados en la circulación de prácticas y cosmovisiones que rebasan los extremos establecidos, y que actúa como un hiato de indecibilidad que perturba los términos monopólicos y reconocidos, permitiendo así la emergencia de sentidos-otros. Según Bhabha, estos entre-medio son lugares de negociación (más que de negación) de campos antagónicos, lo cual ofrece un terreno para construir nuevas condiciones de interpelación y lecturas (traducciones) de la realidad sobre la acción de los sujetos. ${ }^{9}$

\footnotetext{
GUHA, R.; SPIVAK, G. (eds.). Selected Subaltern Studies. New York: Oxford UP, 1988.

MELLINO, Miguel. La crítica poscolonial. Buenos Aires: Paidós, 2008.

7 MIGNOLO, Walter. El pensamiento des-colonial, desprendimiento y apertura: un manifiesto. In: WALSH, Catherine; LINERA, Álvaro; MIGNOLO, Walter (eds.). Interculturalidad, descolonización del estado y del conocimiento. Buenos Aires: Ediciones del Signo, 2006. p. 83-123.

8 MIGNOLO, Walter. Desobediencia epistémica. Buenos Aires: Ediciones del Signo, 2010.

9 BHABHA, Homi. El lugar de la cultura. Buenos Aires: Manantial, 2002. p. 43-45.
} 
Este entre-medio como espacio de negociación y (nuevas) traductibilidades (siguiendo un claro espíritu posestructuralista, más concretamente derrideano), pone de manifiesto lo que Bhabha denomina como "ambivalencia del discurso colonial", lo cual da lugar al fenómeno de mimesis. "El mimetismo emerge como la representación de una diferencia que es en sí misma un proceso de renegación. El mimetismo es, entonces, el signo de una doble articulación; una compleja estrategia de reforma, regulación y disciplina, que se 'apropia' del Otro cuando éste visualiza el poder... [P] royecta una amenaza inmanente tanto sobre el saber 'normalizado' como sobre los poderes disciplinarios". ${ }^{10}$

Esta noción refiere a un "compromiso irónico" con las fuerzas coloniales por parte de los grupos subalternos y las narrativas circulantes dentro de los espacios colonizados. Es la representación del "sujeto de una diferencia que es casi lo mismo, pero no exactamente". En otros términos, invoca la reapropiación de los grupos y sujetos subalternizados tanto del lugar como de los recursos simbólicos y discursivos dentro del marco identitario hegemónico colonial, cuyo fin es depurar su supuesta sutura ontológica, en pos de construir una divergencia con respecto del "sistema" -que se presenta cerrado cuando en realidad no lo es-, desde sus fisuras inherentes, y así posibilitar la construcción de nuevas espacialidades y producciones identitarias. Como se suele decir, es usar las armas del sistema en su contra, mostrando que las cosmovisiones coloniales pueden ser subvertidas al ser utilizadas para propósitos opuestos por los sujetos o grupos subalternos. ${ }^{11}$

Por último, en uno de sus recientes trabajos Homi Bhabha ${ }^{12}$ plantea una ética del reconocimiento para una comunidad paradójica. Remitiendo a Julia Kristeva, Bhabha afirma que toda persona, y por ende toda comunidad, se inscribe en una paradoja: ser lo mismo y lo otro, o sea, nativo y extranjero, ciudadano y forastero al mismo tiempo. Esto de por sí ya implica una deconstrucción de ciertos imaginarios sociales, tales como la homogeneidad identitaria de lo nacional. Se levanta, entonces, el proble-

10 BHABHA, 2002, p. 112.

11 Esta idea también fue trabajada por Walter Mignolo cuando habla de un proyecto descolonial como instancia programática de desprendimiento o delinking de las categorías de conocimiento colonial. Una estrategia de desprendimiento comprende la desnaturalización de los conceptos y los campos conceptuales de la colonialidad. En otros términos, es hacerle el juego al sistema con sus propias reglas. El proceso comienza cuando los actores que habitan las lenguas y las identidades negadas por el Imperio toman conciencia de los efectos de la colonialidad en el ser, el cuerpo y el saber. Aquí la propuesta central de su obra: el pensamiento fronterizo. Esta epistemología evoca a la pluri-versidad y di-versidad de la dinámica entre los espacios de experiencia y los horizontes de expectativa suscriptos en el campo colonial/moderno. El pensamiento crítico decolonial conecta la pluri-versidad de las experiencias encerradas en los marcos coloniales con el proyecto uni-versal del desprendimiento constante de los horizontes imperiales, lo cual construye una propuesta que va más allá de la implementación de un modelo dentro de las categorías modernas (derecha, centro, izquierda), sino una política focalizada en poner en evidencia los espacios subversivos inscriptos en la acción de los agentes colonizados entre las fisuras del sistema imperial. MIGNOLO, Walter. Desobediencia Epistémica. Ver PANOTTO, Nicolás. Religión, política y poscolonialidad en América Latina. Buenos Aires: Miño\&Davila, 2016. p. 24-25.

12 BHABHA, Homi. Nuevas minorías, nuevos derechos. Notas sobre cosmopolitismos vernáculos. Buenos Aires: Siglo XXI, 2013. p. 23-44. 
ma ético del reconocimiento, en el sentido de qué lugar asume esa otredad constitutiva dentro del campo social. Es un desafío a la constitución ontológica de la comunidad.

De aquí Bhabha plantea varios puntos de partida. Primero, que un sujeto es sobre todo sujeto parlante y discursivo. El individuo es portador de derechos de enunciación. De aquí, entonces, que todo acto de enunciación es un acto de performance. El derecho de enunciación no tiene que ver sólo con una operación del lenguaje sino también con la construcción de una serie de prácticas discursivas. Por ello el poder simbólico de los derechos reside en su contenido retórico más que proposicional (Amartya Sen) Los derechos universales - enarbolados como justicia, igualdad, respeto, libertad-son tales en tanto horizontes que permiten una redefinición contante de las agencias sociales, y con ello la emergencia de una pluralidad de voces y la apertura de espacios de litigio por "lo común". De aquí, finalmente, que la ética política tiene que ver con la negociación constante entre lo condicional y lo incondicional. Ambas instancias no son absolutas en sí mismas sino que son atravesadas por una "terceridad" (el tercer espacio significante), o sea, una zona liminal de lo condicional dentro de lo incondicional, que lleva a la ambivalencia y antagonismo significante de tales derechos.

Hablar, entonces, de contingencia y alteridad puede sonar abstracto. Pero una ética de la paradoja apunta a dos elementos centrales: a la noción intersubjetiva de la agencia que destaca la dimensión de lo relacional más que a un individuo abstracto, y segundo, que mientras la idea de alteridad es un desafío en términos de definición ontológica, la noción de performance como presencia concreta de lo alterno en el espacio social, envuelve un desafío directamente político en lo institucional. Por ello, el reconocimiento tiene que ver con negociar con la alteridad que nos constituye y atraviesa. $^{13}$

A partir de estas breves notas, destacamos que un abordaje poscolonial conlleva una redefinición del espacio público, desde el cuestionamiento de las concepciones tradicionales y por sobre todo de las matrices coloniales que trae consigo la cosmovisión política moderna. Podemos decir entonces que, desde una perspectiva poscolonial, el espacio público representa un locus de disputa de sentidos sobre "lo común", donde la noción de homogeneidad (social, política, cultural), con su respectiva naturalización de las jerarquías sociales monopólicas, es cuestionada por los dispositivos hermenéutico-políticos que emergen desde la densidad de los bordes entre-medio manifiestos en la pluralidad de discursos, sujetos e institucionalidades que habitan y circulan en el campo. Por ende, una crítica política significa dar cuenta y visibilizar la pluri-versidad que compone un espacio público, no sólo en el marco de una "exposición" de partes desconexas, sino como una manera de crear un contorno liminal de inter-conexiones, donde el Otro no sólo representa una terceridad que rompe con las dicotomías (y con ello el estatus de cualquier elemento particular) sino que evidencia los límites ontológicos de las visiones hegemónicas coloniales.

${ }_{13}$ BHABHA, 2013, p. 37. 


\section{Dios-entre-medio: una lectura teológica poscolonial}

El desafío de esta definición de lo público a la teología se presenta la construcción de un marco epistemológico que permita identificar y "jugar" con esas espacialidades entre-medio, como aperturas críticas de sentido y práctica. En términos disciplinares, existe el peligro de generar una propuesta más que se incorpore como un ídolo en el panteón de la pluralidad teológica desde esta nueva mirada, sin necesariamente dar cuenta del sentido mismo de lo heterogéneo que construye, atraviesa y tensiona todo discurso teológico. Como advierte David Tracy ${ }^{14}$, aquí no estamos hablando de una disputa entre teologías modernas y posmodernas, ya que, desde una crítica poscolonial, en muchos casos ambas pueden llegar a partir del "olvido del otro", desde el enmarque moderno y occidental que puedan llegar a tener.

El desafío reside en dejar la simple ramificación de narrativas particulares (lo cual no es necesariamente negativo) y retomar el propio objeto de la teología. Nos referimos concretamente a la tarea de poscolonizar lo divino ${ }^{15}$ como un ejercicio de relectura articulada de lo plural, como también de apelar al sentido de trascendencia en el ontos divino como operación fundadora de diferencia. En otros términos, implica priorizar una teología crítica sobre Dios en clave poscolonial. Para este ejercicio, deseamos proponer cuatro marcos generales desde los cuales emprender esta tarea. El primero es destacar la dimensión mimética de la teología cristiana. La historia de la iglesia da cuenta de que cómo los símbolos teológicos de su tradición fueron y son utilizados desde propósitos e imaginarios muy disímiles, pasando, por ejemplo, desde la imposición de la cruz a través de la conquista, al sentido de liberación en el ministerio de Jesús con los oprimidos.

Señalar esta "ambivalencia" del discurso teológico cristiano, tiene directa relación con su capacidad mimética, lo cual implica no sólo destacar una dimensión hermenéutica sino también política. O si se quiere, una hermenéutica del desprendimiento. Esta capacidad flotante que poseen los símbolos cristianos los hacen capaces de visibilizar sujetos y contextos, como también cuestionar la falsa sutura ontológica de las adjudicaciones hegemónicas. Es decir, la diversidad de reapropiaciones teológicas dan cuenta del locus, y con ello de la "opción" hermenéutica que asumen diversos grupos enfrentados en un espacio (global) de disputa. ${ }^{16}$ Por último, esto también recalca que los campos de la teología -sea la exégesis, la cristología, la pneumatología, la escatología, etc.- no deben ser entendidos como marcos dogmáticos que buscan una clausura "renovada" para ser aplicados a otro contexto (lo que sería una falsa hermenéutica) sino más bien poner a disposición un conjunto de ejes de traductibilidad que partan de especificidades disciplinarias pero que abren nuevas llaves de representación.

14 TRACY, David. On Naming the Present. God, Hermeneutics, and Church. Maryknoll: Orbis, 1994. p. 3-24.

15 LARTEY, Emmanuel. Postcolonializing God. An African Practical Theology. London: SCM, 2013; PANOTTO, 2016, p. 125-137.

${ }^{16}$ RIEGER, Joerg. Globalization and theology. Nashville: Abingdon, 2002. 
El segundo elemento es la necesaria tarea de des-occidentalizar la persona divina. Las imágenes predominantes en la teología moderna responden a una lógica occidental. Con ello nos referimos al predominio de una visión esencialista de Dios, muy en línea con ese primer motor inmóvil aristotélico que hace de lo divino una entidad ontológica dominante en la historia. Dicho concepto no anida solo en teologías conservadoras sino también en perspectivas críticas, en línea, por ejemplo, con el cuestionamiento que trae Ivone Gebara sobre la presencia de ese Dios Liberador de la teología de la liberación, que se presenta desde un proyecto histórico inmanente pero transcendentalizado en su estatus ontológico. ${ }^{17}$

Como afirma Philip Clayton, necesitamos de un Dios "post-dicotómico". ${ }^{18} \mathrm{La}$ lógica dicotómica de la modernidad es una lógica maquiavélica. Sirve para ubicar un espacio de poder excluyente con un resto funcional a esa delimitación. Un Dios poscolonial parte del principio kenótico de la encarnación (Fil 2) como un gesto de hospitalidad y apertura a lo alterno y radicalmente "mundano", despojado de todo poder centralizador, para manifestar lo divino en el encuentro con lo humano. Es, en palabras de Mayra Rivera, la expresión de una trascendencia relacional ${ }^{19}$, donde el Dios-Otro nos invita a asumir la alteridad histórica, pero no desde un lugar de poder ni tampoco desde un no-lugar abstracto sino desde el intersticio de un encuentro que excede las bifurcaciones funcionales.

Es aquí donde podemos remitir al principio de "opción preferencial” sostenido por la teología de la liberación, pero no ya desde una lógica dicotómica (a veces presente en esta corriente) de "uno sobre otro" sino desde un posicionamiento que deconstruye lo absoluto de cualquier lugar. Este es el tercer eje: necesitamos ubicar a Dios en un locus de sub-alternidad como nuevo locus ontológico. Como hemos propuesto en otro lugar, ${ }^{20}$ la revelación de Dios a partir de ese "resto" escatológico (los pobres, los excluidos, los desplazados) que proyecta la esperanza y moviliza a la transformación histórica, no debe ser identificado como la encarnación mesiánica en un sector, grupo o sujeto específico sino como una lógica de revelación histórica de Dios, donde lo subalterno no acentúa sólo una representación particular sino asume la acción de Dios desde la "reserva de sentido" (Ricoeur) o su exceso constituyente. En otras palabras, la opción divina por lo excluido se presenta como un dispositivo de revelación desde un espacio de "terceridad" que rompe con las dicotomías excluyentes del discurso teológico colonial.

17 GEBARA, Ivonne. Intuiciones ecofeministas. Ensayo para repensar el conocimiento y la religión. Madrid: Trotta, 2000.

${ }^{18}$ CLAYTON, Philip. The God Who Is (Not) One: Of Elephants, Blind Men, and Disappearing Tigers. In: BOESEL, Chris; ARIARAJAH, Wesley. Divine Multiplicity. Trinities, Diversities, and the Nature of Relation. New York: Fordham University Press, 2014. p. 31.

19 RIVERA, Mayra. The Touch of Transcendence: A Postcolonial Theology of God. Louisville: Westminster John Knox, 2008.

${ }^{20}$ PANOTTO, Nicolás. Teología como sensibilidad crítica sobre la (hétero)práxis. Desafíos hermenéuticos hacia dentro de la teología de la liberación. Revista de Interpretación Bíblica Latinoamericana, v. 77, n. 1, p. 167-191, 2018. 


\section{Más allá de lo común o lo común como trascendencia: líneas para una teología pública poscolonial}

Hablar, entonces, de una teología pública en clave poscolonial, es proponer un quehacer teologal que proyecta la hospitalidad como un acto político ${ }^{21}$, donde la apertura al Otro es comprendida no sólo desde un encuadre de responsabilidad ética sino también como la inscripción de un locus donde la diferencia, la diversidad y el acercamiento a la alteridad constituyen la inauguración de un campo hermenéutico que disputan las epistemes coloniales hegemónicas a partir de ese "tercer espacio" suscrito en el valor de la pluralidad. Dios es la presencia que se mueve en el entre-medio de las fronteras instituidas, buscando emerger desde las rendijas presentes en todo espacio de sentido, para dar cuenta que lo que se dice suturado como cierto y verdadero (jerarquizaciones, cosmovisiones, delimitaciones, prácticas, estigmas) e impuesto a través de poderes instituidos, nunca podrá clausurar el exceso que constituye su trascendencia. Una trascendencia que se presenta intrínsecamente política al ser una presencia crítica de los sentidos monopolizados e inauguradora de nuevas expresiones sociales.

Es un llamado a un quehacer que radicaliza la vinculación entre teología e historia, donde esta última no es simplemente un escenario delimitado por fronteras sino un plano con infinitas líneas de fuga (Deleuze) que se entrecruzan en un movimiento constante entre caminos y descentramientos. En palabras de Catherine Keller, "si el discurso teológico quiere vivir, debe hablar entre los intersticios de las densidades históricas del texto y sus esperanzas creativas". ${ }^{22}$ La dimensión pública de la teología, entonces, tiene directa relación con una lectura descolonizadora, ya que apela a la espacialidad desde la "frontera interna" 23 que habilita nuevas prácticas y apela a una condición agonística de lo político, a saber, donde las partes que componen lo público no se atienen a una lógica amigo-enemigo, sino a la de adversarios que forman parte de un mismo estatus de diferencia constitutiva.

Una teología pública poscolonial tiene como tarea central deconstruir las dicotomías que reinan tanto en la propia teología cristiana como en la sociedad (pos) moderna en general. Las dicotomías sirvieron para instituir esferas de dominio a través de la delimitación de categorizaciones en torno a las dinámicas sociales. Con ello, la empresa colonial en tanto cosmovisión epistémica construyó una base para la circunscripción de jerarquías sociales (especialmente de género), prácticas políticas excluyentes, procesos de racialización, entre otras. Por ello, una teología pública que interpela esa "terceridad" siempre presente en toda construcción política, busca una actitud crítica constante, pero no con el objetivo del cuestionamiento como fin en sí mismo, sino como una radicalización de la convivencia plural, donde todas las partes

${ }^{21}$ DERRIDA, Jacques. Politicas de la amistad. Madrid: Trotta, 1998; SHEPHERD, Andrew. The gift of the Other. Levinas, Derrida, and a Theology of Hospitality. Oregon: Pickwick, 2014.

22 KELLER, C. Face of the Deep. A Theology of Becoming. London; New York: Routledge, 2003. p. xviii.

${ }^{23}$ LACLAU, Ernesto. La razón populista. Buenos Aires: FCE, 2005. 
son incluidas en un diálogo abierto. Como plantean Catherine Keller, Michael Nausner y Mayra Rivera:

Una teología que descoloniza los espacios-entre de nuestra interdependencia desplazará su tarea desde la protección de fronteras al cruce de fronteras: una metáfora "extraña" para el cristianismo. La tarea de una teología poscolonial no será apuntalar las barreras entre lo cristiano y lo no cristiano, lo santo y lo profano, la iglesia y el mundo, lo ético y lo inmoral, incluso el Creador y la creación. Tampoco será simplemente para demolerlos. Pondremos, más bien, atención cuidadosa a lo que sucede en todos estos pasos intermedios ${ }^{24}$.

Una de las temáticas centrales para una teología pública poscolonial es abordar la cuestión del sujeto político. ${ }^{25}$ Este tema ha sido ampliamente desarrollado por el grupo del Departamento Ecuménico de Investigaciones (DEI), más concretamente por Franz Hinkelammert ${ }^{26}$, Jung Mo Sung ${ }^{27}$ y Hugo Assmann ${ }^{28}$. El énfasis entre estos tres autores se asemeja en varios aspectos, aunque en otros se contrapone. Podríamos decir que existe un consenso entre ellos sobre la noción de sujeto como un concepto antropológico que enfatiza la dimensión disruptiva de las identidades, en medio de una instancia de agenciamiento (subjetivación) dentro de las estructuras de poder. Fue Assman quien radicalizó críticamente algunos de estos postulados, especialmente respondiendo a Hinkelammert, sosteniendo que es necesario que dicha dimensión política inherente al sujeto esté atravesada por la dimensión afectiva y corporal. Dejar este elemento de lado, puede llevar a extrapolar el Sujeto Universal moderno con algo similar, aunque a partir de sujetos conceptualizados desde un pragmatismo militante. Este último elemento que traza Assman es esencial a la hora de plantear un concepto de sujeto poscolonial: los dos elementos mencionados anteriormente con respecto a la dimensión diaspórica de la poscolonialidad, involucra entender al sujeto desde el dolor que conllevan no sólo las "heridas coloniales" sino también los propios procesos de desplazamiento.

La incapacidad de manejar la dimensión pasional y afectiva de lo político, inherente a cualquier sujeto, acarrea la conformación de polarizaciones -muy presentes en nuestros tiempos- que desgastan las relaciones sociales, que llevan al descreimiento político, y con ello trae de regreso discursos que propagan la preferencia de modelos políticos dictatoriales (fomentando así golpes de Estado, golpes pseudo-

${ }^{24}$ KELLER Catherine; NAUSNER, Michael; RIVERA, Mayra. Postcolonial Theologies: Divinity and Empire. St. Louis: Chalice, 2004. p. 14.

${ }_{25}^{25}$ PANOTTO, Nicolás. Hacia una teología del sujeto político. San José: UNA, 2012.

${ }^{26}$ HINKELAMMERT, Franz. El grito del sujeto. San José: DEI, 1998.

${ }^{27}$ MO SUNG, Jung. Sujeto y sociedades complejas. San José: DEI, 2005.

${ }^{28}$ ASSMANN, Hugo. Apuntes sobre el tema del sujeto. In: AAVV. Perfiles teológicos para un nuevo milenio. San José: DEI; CETELA, 2004. p. 115-146. 
-constitucionales, el regreso de regímenes militares) con tal de suturar todo conflicto de interpretaciones. ${ }^{29}$

Podemos resumir, entonces, que una teología pública poscolonial parte de un marco donde la condición diaspórica del sujeto es entendida como un contexto de ambivalencia constituyente, entre una condición dinámica propia de su ser-en-movimiento y el inevitable atravesamiento de una diferencia colonial que lo confronta con estructuras excluyentes. De esta manera, los procesos de identificación subjetiva se dan en esta tensión dislocante entre lo recibido inexcusablemente por los procesos coloniales y las posibilidades de subversión propios de los mecanismos de subjetivación, siendo inclusive una instancia de desplazamiento forzado, de victimización, de desestabilización del estatus ontológico que sostiene el lugar de sutura del sujeto. Comprender esta posición contingente es reconocer, paradójicamente, un lugar de poder que se proyecta desde ese entre-medio inherente a cualquier espacio de exclusión como posibilidad-de-ser.

Llevando estas ideas a contextos o acciones programáticas más concretas, podríamos mencionar algunos elementos, especialmente a partir de la relación entre espacio público y fenómeno religioso en la actualidad. El primer planteo es que una teología pública poscolonial asume una actitud crítica frente a los conceptos modernos de secularización, los cuales distan de abordar políticamente la diversidad social que dicen representar. Primeramente hay que preguntarse si esta categoría, la cual es una invención moderna, continúa siendo pertinente para analizar los complejos fenómenos de las creencias en la actualidad. ${ }^{30}$ Pero más allá de ese debate (por cierto, muy necesario), lo que puntualizamos es el hecho de que en muchos abordajes filosóficos se continúa trazando la idea de secularización como una instancia intrínsecamente plural. Esto dista de ser real: muchos de los abordajes en este campo siguen hablando de la posibilidad de un concepto "neutral" del espacio público, donde las particularidades identitarias (tanto religiosas como de otro tipo) son absorbidas por una abstracta "razón pública", que al final termina demarcando un conjunto de fronteras fijas y posiciones de poder. ${ }^{31}$ Más aún, los conceptos tradicionales de secularización parten de nociones abstractas de subjetividad, que distan de comprender al sujeto en la necesaria complejidad que impone una diferencia colonial crítica con los marcos modernos hegemónicos. Como dice Alessandro Ferrara, estas perspectivas terminan legitimando un monopluralismo liberal, que "parecen admitir el pluralismo en muchas áreas, excepto cuando se trata de las razones por las que el pluralismo debe ser

${ }^{29}$ MOUFFE, Chantal. Política y pasiones. Las apuestas de la democracia. In: ARFUCH, Leonor (comp.). Pensar este tiempo. Espacios, afectos, pertenencias. Buenos Aires: Paidós, 2005. p. 86-87.

30 SEMÁN, Pablo. La secularización entre los cientistas de la religión del Mercosur. CAROZZI, Maria Julia; CERNADAS, Cesar Ceriani. Ciencias sociales y religión en América Latina, Buenos Aires: Biblos, p. 41-59, 2007.

31 Ver la conocida discusión al respecto entre Charles Taylor y Jürgen Habermas en TAYLOR, Charles. Porqué necesitamos una redefinición radical del secularismo, y en Diálogo entre Jürgen Habermas y Charles Taylor. In: MENDIETA, Eduardo (org.). El poder de la religión en la esfera pública. Madrid: Trotta, 2011. p. 39-68. 
aceptado... es el nombre de esa mezcla de fundacionalismo pluralista, que en último término se reduce a la fundamentación de la tolerancia y a la autonomía individual. ${ }^{32}$

Esto nos lleva a un segundo planteo, más bien relacionado con cómo definimos al sujeto creyente: una teología pública poscolonial apela a un re-encantamiento ${ }^{33}$ de la experiencia de fe, donde lo religioso trasciende la dicotomía moderna que la encierra en lo privado, para ser entendida como una forma de encarar la vida pública a través de la alteridad divina como una ubicación de tercerización crítica. Esto es lo que Sallie McFague denomina como la necesidad de re-mitificar la teología, en contraposición a la empresa desmitologizadora de la modernidad. ${ }^{34}$ La filósofa Victoria Camps, por su parte, afirma que "la religión, como los mitos, además de constituir un primer intento de dar razón de lo inexplicable, pone de manifiesto la capacidad y el anhelo del ser humano de trascender lo inmediato, mirando más allá de sí mismo, o profundizando en su interior, en busca de un sentido que permita apaciguar, o aceptar, la zozobra de la existencia finita. ${ }^{35}$

La teología pública tiene por objetivo resaltar la dimensión de trascendencia, alteridad e imaginación histórica de la fe y lo religioso como una práctica de crítica política, a partir de la posibilidad de pensar el discurso religioso desde una epistemología decolonial o como un pensamiento-otro "que se construye desde otro lugar, con un lenguaje otro, sostenido en una lógica otra y concebido desde las fronteras del sistema mundo colonial/moderno. Para ello se asienta tanto en la crítica al occidentalismo/eurocentrismo desde su condición marginal a él y por lo tanto no etnocida, como en la crítica a la misma tradición excluida en la que se radica pero que requiere ser revisada. ${ }^{36}$ Esta tarea responde a un quehacer teologal que potencia las implicancias estéticas del sujeto creyente, es decir, la posibilidad de ubicarse en una dimensión existencial entre-medio como forma de comprender tanto la subjetividad como un proceso cambiante, y a partir de allí la propia historia, con sus vivencias y contextos, dentro de un juego de desplazamientos fronterizos, que apelan a nuevas militancias, nuevas experiencias de la fe, nuevos escenarios posibles. De esta manera, lo religioso, la utopía y la crítica política juegan juntas en un marco de dislocación. ${ }^{37}$

${ }^{32}$ FERRARA, Alessandro. El horizonte democrático. El hiperpluralismo y la renovación del liberalismo político. Barcelona: Herder, 2014. p. 133.

${ }^{33}$ Refiérase a la idea de "desencantamiento del mundo" en Max Weber.

${ }^{34}$ MCFAGUE, Sallie. Modelos de Dios. Teología para una era ecológica y nuclear. Santander: Sal Terrae, 1994.

${ }^{35}$ CAMPS, Victoria. La secularización inacabada. In: GAMPER, Daniel. La fe en la ciudad secular. Laicidad y democracia. Madrid: Trotta, 2014. p. 13.

36 PALERMO, Zulma. Conocimiento "otro" y conocimiento del otro en América Latina. Estud. - Cent. Estud. Av., Univ. Nac. Córdoba, n. 21, p. 82, 2009. On-line. Acesso em: 26 dez. 2017.

${ }^{37}$ Como resume Schneider, una de las teólogas poscoloniales que más ha profundizado sobre "una teología de Dios": "Esto es lo que distingue a la teología de otras empresas intelectuales modernas: hay una inversión total en traducir los símbolos centrales y las declaraciones de fe en contextos de plausibilidad que vinculan la profundidad de los símbolos con las estructuras de significación efectivas de las experiencias y culturas vividas". SCHNEIDER, L. Beyond Monotheism. A Theology of Multiplicity. London; New York: Routledge, 2008. p. 4. 
Por último, una teología pública poscolonial apela a una metodología polidoxa de la misión, donde la diferencia religiosa se transforma en un espacio de encuentro y transformación socio-políticas. El concepto de polidoxia lo utilizan algunos círculos teológicos para destacar el principio de multiplicidad a la hora de hablar de fe y teología. La polidoxia intenta ir más allá del sentido llano de multiplicidad, ya que el término no refiere simplemente a una diversidad en términos cuantitativos, sino a las implicancias sobre las interacciones entre los diversos elementos. "Teológicamente, intentamos una enseñanza confesamente múltiple de la multiplicidad divina. $\mathrm{Su}$ hermenéutica y ontología se implican y explican entre sí. Ambas, desde la realidad y la interpretación teológica sobre la realidad, suponen una interconexión profunda, una relacionalidad constitutiva, entre ellas y los Otros. Por multiplicidad, entonces, no nos referimos a muchos, a una pluralidad de otros separados; ni por relacionalidad nos referimos a un pantano de indistinción. Más bien, las líneas de diferenciación que encontramos en una lógica de multiplicidad relacional resiste la predictibilidad". ${ }^{38}$

En otros términos, el sentido de polidoxia pretende ser una "tercera vía" entre absolutismo y relativismo ${ }^{39}$, planteando la realidad de lo plural -y con ello la necesidad de la auto-determinación de las partes- pero desde una mirada radical sobre la co-dependencia y la inter-conexión entre ellas. Aquí lo divino se manifiesta no como la legitimación de una de las particularidades por sobre el resto, ni tampoco como una suma entre muchas, sino como la presencia que funda estas interconexiones, a partir de las cuales a su vez des-funda cualquier posibilidad de absolutización ontológica de alguna de ellas. Dios es la posibilidad-de-ser en la posibilidad-de-relacionarnos, así como lo divino - desde una perspectiva cristiana- es una comunidad trinitaria que descoloca la primacía de los binomios enajenantes desde el movimiento disruptivo y "tercerizador" del Espíritu.

Esto nos lleva entonces a plantear una misionología polidoxa que tiene varias implicancias en términos prácticos. Como propone Marion $\mathrm{Grau}^{40}$, los espacios de "encuentro misional" deben ser entendidos como "zonas de interacción". Este planteo tiene de por sí una dimensión de crítica poscolonial, al entender lo misional como una empresa que se resiste a todo determinismo e imposición religiosa, buscando el diálogo y el enriquecimiento mutuos. Como planteamos, esto no acepta la anulación de la identidad cristiana, sino todo lo contrario: más bien, sugiere que el valor del cristianismo en tanto particularidad identitaria -fundada y des-fundada por la acción constante del Dios-comunidad-siempre-Otro en el Espíritu- reside en el enriquecimiento de la interacción en estas zonas de encuentro, cuyo propósito principal es el cuestionamiento de las relaciones coloniales sobre las sociedades. Aquí un elemento central para la teología pública: la importancia del diálogo interreligioso como una política pública, que no sólo hace visible la "diversidad" de creencias en un grupo

38 KELLER, Catherine; SCHNEIDER, Laurel (eds.). Polydoxy: theology of multiplicity and relation. London: Routledge, 2011. p. 2.

${ }^{39}$ CLAYTON, 2014, p. 25.

40 GRAU, Marion. Rethinking Mission in the Postcolony. Salvation, Society and Subvertion. London: T\&T Clark, 2011. 
sino que habilita un espacio de encuentro que aporta a la construcción de relaciones democráticas y enriquece la mirada teológica propia de cada expresión de fe.

En este sentido, la dimensión polidoxa de la misión no sólo se centra en una perspectiva religiosa, sino en la espiritualidad que asume la inter-conexión de todas las partes del espacio público como un escenario donde lo divino se mueve e interactúa. Aquí los "públicos" de la teología pública -iglesia, sociedad y academia ${ }^{41}$ - son comprendidos no sólo como escenarios desconexos y recipientes de acciones "externas", sino como un locus donde diversos agentes, narrativas, abordajes, cosmovisiones, etc. se entienden en una relacionalidad inter-dependiente que pone de manifiesto los espacios entre-medio de las fronteras disciplinares, sociales, religiosas, políticas y culturales a través de las cuales lo divino se pasea libremente, creando más fisuras, tensiones y caminos para la manifestación de lo novedoso (sea en términos discursivos, relacionales, institucionales, políticos, etc.)

\section{Conclusiones}

En este artículo hemos partido de una definición de poscolonialidad como el reconocimiento y la construcción de un locus ambivalente, donde las dinámicas sociales no se gestan prioritariamente por la oscilación entre modelos sociales sino por los espacios entre-medio que fisuran todas las relaciones comunitarias, deconstruyendo así los sentidos y prácticas establecidas, para dar lugar a nuevas miradas, nuevas prácticas y nuevos escenarios. En este sentido, planteamos que lo público, desde una mirada poscolonial, es el lugar donde - tras la deliberación por las demandas y las inter-conexiones entre sus diversos agentes- germina una tensión fundante, que lo hace sobre todas las cosas un espacio hermenéutico de disputa de sentidos por "lo común”. Estas dinámicas representan por sí mismas la dimensión política inherente a cualquier grupo. Más aún, la radicalización (crítica) de esta dimensión significa mantener las fronteras abiertas a través de la visibilización de los lugares entre-medio, a partir del reconocimiento de la pluralidad, el cual no se pone de manifiesto como un discurso "políticamente correcto" (como lo haría una visión multiculturalista liberal) sino como la creación de dispositivos que den cuenta de dicha diversidad en términos de dinámicas sociales, prácticas políticas, institucionalidades $\mathrm{y}$, sobre todo, instancias de diálogo, encuentro y hospitalidad radical.

De aquí planteamos la necesidad de una teología que se enfoque en desarrollar una visión sobre lo divino como la presencia que se mueve sobre y crea estas espacialidades entre-medio. Ello involucra una tarea de crítica y una deconstrucción de las dicotomías y visiones fundacionales - propias de la teología cristiana colonial y moderna heredadas-, hacia una visión mística, mimética, y que proyecta los lugares de exclusión, no como escenarios desde donde crear una lógica antagónica, sino como una teología del resto, donde lo que queda "afuera" (sea de manera forzada o como

${ }^{41}$ TRACY, David. A imaginação analógica. A teologia cristã e a cultura do pluralismo. São Leopoldo: Unisinos, 2006. 
proceso de transformación identitaria) representa una "terceridad" que amenaza la sutura de lo dado, así como la trascendencia, alteridad e indecibilidad de Dios cuestionan las imágenes establecidas, o la propia cruz confronta al Imperio desde su símbolo sufriente y débil, pero no con el objetivo de quedar en la nada misma sino para abrir nuevos horizontes y prácticas.

Esto trae consigo muchos desafíos para una teología pública. Por un lado, radicaliza el lugar del sujeto teológico (tal como ya lo propuso la teología de la liberación) planteando la presencia de estas sujeticidades, no como simples enunciaciones determinadas en un lugar y contexto particulares, sino como la representación de un espacio ontológico que promueve el movimiento y el proceso, desde nuevas epistemologías (es decir, desde la diversidad de modos de construcción del sentido) donde todas las áreas de lo humano, lo no-humano, lo corporal, lo afectivo y lo relacional entran en juego (en contraposición a un concepto abstracto de la subjetividad moderna) También trae directas consecuencias sobre una valoración re-encantadora de la religiosidad y la espiritualidad, entendidas no sólo como formas institucionales que viabilizan creencias particulares, sino desde el poder hermenéutico, relacional, escatológico y afectivo que poseen sus elementos constitutivos, a saber, la noción de lo trascendente, lo mitológico, lo ritual y lo simbólico. A su vez, esto conlleva una nueva manera de concebir las dinámicas hacia dentro del espacio público desde una mirada de la fe, donde la inter-conexión de todas las partes dejan de ser abordadas por una mirada pragmática y categórica, para ser entendidas como un espacio complejo, difuso, pero esperanzador, en su posibilidad constante de cambio, y con ello de poner de manifiesto este Deus Absconditus ${ }^{42}$ que se oculta, no para esconderse sino para mantener esa reserva de sentido que abre la historia y dinamiza la condición política del espacio público hacia otros horizontes.

\section{Referencias}

ASSMANN, Hugo. Apuntes sobre el tema del sujeto. In: AAVV. Perfiles teológicos para un nuevo milenio. San José: DEI; CETELA, 2004. p. 115-146.

BHABHA, Homi. El lugar de la cultura. Buenos Aires: Manantial, 2002.

. Nuevas minorías, nuevos derechos. Notas sobre cosmopolitismos vernáculos. Buenos Aires: Siglo XXI, 2013.

CAMPS, Victoria. La secularización inacabada. In: GAMPER, Daniel. La fe en la ciudad secular. Laicidad y democracia. Madrid: Trotta, 2014. p. 21-39.

CHUNG, Paul. Postcolonial public theology. Oregon: Cascade groups, 2016.

CLAYTON, Philip. The God Who Is (Not) One: Of Elephants, Blind Men, and Disappearing Tigers. In: BOESEL, Chris; ARIARAJAH, Wesley. Divine Multiplicity. Trinities, Diversities, and the Nature of Relation. New York: Fordham University Press, 2014. p. 19-37.

DERRIDA, Jacques. Políticas de la amistad. Madrid: Trotta, 1998.

42 PANOTTO, Nicolás. Dios y lo público. Hacia una teología política latinoamericana desde una relectura luterana contemporánea. In: AAVV. Reforma religiosa y transformación social. San José: UBL, 2017. p. 283-306. 
FERRARA, Alessandro. El horizonte democrático. El hiperpluralismo y la renovación del liberalismo político. Barcelona: Herder, 2014.

GEBARA, Ivone. Intuiciones ecofeministas. Ensayo para repensar el conocimiento y la religión. Madrid: Trotta, 2000.

GRAU, Marion. Rethinking Mission in the Postcolony. Salvation, Society and Subvertion. London: T\&T Clark, 2011.

GUHA, R.; SPIVAK, G. (eds.). Selected Subaltern Studies. New York: Oxford UP, 1988.

HINKELAMMERT, Franz. El grito del sujeto. San José: DEI, 1998.

KELLER, C. Face of the Deep. A Theology of Becoming. London; New York: Routledge, 2003. KELLER, Catherine; SCHNEIDER, Laurel (eds.). Polydoxy: theology of multiplicity and relation. London: Routledge, 2011.

KELLER, Catherine; NAUSNER, Michael; RIVERA, Mayra. Postcolonial Theologies: Divinity and Empire. St. Louis: Chalice, 2004.

LACLAU, Ernesto. Misticismo, retórica y politica. Buenos Aires: FCE, 2002.

. La razón populista. Buenos Aires: FCE, 2005.

LARTEY, Emmanuel. Postcolonializing God. An African Practical Theology. London: SCM, 2013.

MCFAGUE, Sallie. Modelos de Dios. Teología para una era ecológica y nuclear. Santander: Sal Terrae, 1994.

MARCHART, Oliver. El pensamiento politico posfundacional. Buenos Aires: FCE, 2009.

MELLINO, Miguel. La crítica poscolonial. Buenos Aires: Paidós, 2008.

MIGNOLO, Walter. El pensamiento des-colonial, desprendimiento y apertura: un manifiesto. In: WALSH, Catherine; LINERA, Alvaro; MIGNOLO, Walter (eds.). Interculturalidad, descolonización del estado y del conocimiento. Buenos Aires: Ediciones del Signo, 2006. p. 83-123. . Desobediencia epistémica. Buenos Aires: Ediciones del Signo, 2010.

MOUFFE, Chantal. Política y pasiones. Las apuestas de la democracia. In: ARFUCH, Leonor (comp.). Pensar este tiempo. Espacios, afectos, pertenencias. Buenos Aires: Paidós, 2005. p. 77-97. MO SUNG, Jung. Sujeto y sociedades complejas. San José: DEI, 2005.

PALERMO, Zulma. Conocimiento "otro" y conocimiento del otro en América Latina. Estud. Cent. Estud. Av., Univ. Nac. Córdoba, n. 21, p. 79-90, 2009. On-line. Acesso em: 26 dez. 2017. PANOTTO, Nicolás. Hacia una teología del sujeto político. San José: UNA, 2012.

2016. . Religión, política y poscolonialidad en América Latina. Buenos Aires: Miño\&Davila,

. Dios y lo público. Hacia una teología política latinoamericana desde una relectura luterana contemporánea. In: AAVV. Reforma religiosa y transformación social. San José: UBL, 2017. p. 283-306.

. Teología como sensibilidad crítica sobre la (hétero)práxis. Desafíos hermenéuticos hacia dentro de la teología de la liberación. Revista de Interpretación Bíblica Latinoamericana, v. 77, n. 1, p. 167-191, 2018.

RIEGER, Joerg. Globalization and theology. Nashville: Abingdon, 2002.

RIVERA, Mayra. The Touch of Transcendence: A Postcolonial Theology of God. Louisville: Westminster John Knox, 2008.

RIVERA-PAGAN, Luis. Essays from the Diaspora. Chicago: Lutheran School of Theology, 2002. SCHNEIDER, L. Beyond Monotheism. A Theology of Multiplicity. London; New York: Routledge, 2008.

SEMÁN, Pablo. La secularización entre los cientistas de la religión del Mercosur. In: CAROZZI, Maria Julia; CERNADAS, Cesar Ceriani. Ciencias sociales y religión en América Latina. Buenos Aires: Biblos, 2007. p. 41-59. 
SHEPHERD, Andrew. The gift of the Other. Levinas, Derrida, and a Theology of Hospitality. Oregon: Pickwick, 2014.

TAYLOR, Charles. Porqué necesitamos una redefinición radical del secularismo y Diálogo entre Jürgen Habermas y Charles Taylor. In: MENDIETA, Eduardo (org.). El poder de la religión en la esfera pública. Madrid: Trotta, 2011. p. 39-68.

TRACY, David. On Naming the Present. God, Hermeneutics, and Church. Maryknoll: Orbis, 1994. p. 3-24.

. A imaginação analógica. A teologia cristã e a cultura do pluralismo. São Leopoldo: Unisinos, 2006. 